\title{
Safety of users in road evacuation: supply and demand-supply interaction models for users
}

\author{
A. Vitetta, G. Musolino \& F. A. Marcianò \\ Department of Computer Science, Mathematics, \\ Electronics and Transportation, \\ Mediterranea University of Reggio Calabria, Italy
}

\begin{abstract}
In this paper some results obtained in the SICURO research project carried out by the Laboratory for Transport Systems Analysis (LAST) of Mediterranea University of Reggio Calabria (Italy) are presented. Microscopic models able to simulate supply and demand-supply interaction of a road transportation system in emergency conditions are described. A microscopic link model (car-following) is specified and calibrated. Parameters are calibrated from data observed during a real simulation of evacuation executed in the test site of Melito Porto Salvo (Italy). A computer application is performed in order to reproduce the evacuation phases observed. Some indicators for testing the performance of a road transportation network in emergency conditions are defined and estimated.
\end{abstract}

Keywords: evacuation, microscopic approach, link model.

\section{Introduction}

This paper presents some results obtained in the research project entitled SICURO (supported by the Calabria Regional Authority) carried out by the Laboratory for Transport Systems Analysis (LAST) of the Mediterranea University of Reggio Calabria (Italy). The general objective of the project was risk reduction in urban areas in terms of exposure through the definition and the implementation of evacuation procedures.

One of the activities concerns the specification and calibration of models able to simulate transport supply and demand-supply interaction when a population has to be evacuated due to a forthcoming disaster. In such a context, where 
temporary over-saturation of some transportation supply elements, queue formation and dispersion occur, Dynamic Traffic Assignment (DTA) methods and procedures become necessary. They can have different models or specifications: pseudo-dynamic [1], mesoscopic [2] and microscopic, presented in this paper.

Microscopic traffic flow models belong to two different classes:

- link models, that simulate the interactions among vehicles on each link of the network;

- node models, that simulate the interactions among vehicles on each node of the network (signalized and non-signalized intersections, merging and diverging areas, toll plaza areas, ...).

Link models can be divided into:

- car-following models $[3,4]$, that simulate the movement of each vehicle and the interaction with vehicles travelling dowstream on the same lane;

- lane-changing models [5], that simulate the interactions among vehicles travelling on different lanes.

Node models can be divided into:

- models for signalized nodes [6], which can be macrocospic, for an aggregate analysis of node performances, and microscopic, for a disaggregate analysis of node performances, simulating explicitly every driver behaviour;

- models for non-signalized nodes [7], based on the gap-acceptance model.

Path choice models [8] requires the definition of the path choice set and the path choice models. The path choice set is generally defined in a behavioural way, in other words, selecting admissible paths according to the driver's behavioural rules. Paths inside the path choice set can be variable or fixed.

Path choice models, on variable or fixed path choice set, can be:

- pre-trip, when the driver chooses the path according to the origin, the destination and departure time, before starting the trip;

- $\quad$ en-route, when the driver modifies, during the trip, his path on the basis of current traffic conditions on the network.

Among path choice models, we can distinguish two types of models:

- deterministic, if the driver chooses the path with the minimum generalized cost;

- $\quad$ stochastic, if the driver associates a probability to each path belonging to the path choice set.

A detailed classification of microscopic models is presented in $[9,10]$. In this paper microscopic models able to simulate supply and demand-supply interaction of a road transportation system in emergency conditions are presented.

The paper is structured as follows: in section 2 some definitions and notation are introduced and the microscopic traffic model used is presented; section 3 describes data acquisition and model calibration procedures, and section 4 reports the application performed in order to reproduce evacuation observed. In conclusion, some results and prospects for further research are highlighted. 


\section{Models}

In this section we present the models applied for the simulation of evacuation.

\subsection{Definitions and notations}

Variables of the car-following model used are:

- h, spatial headway between vehicles travelling on the same lane of a link;

- $\mathrm{v}$, vehicle speed on link;

- $\mathrm{k}$, density.

Parameters of the car-following model are specified as functions of five link attributes:

- $\mathrm{v}_{0}$, free speed;

- $\mathrm{v}_{\mathrm{CR}}$, speed at capacity;

- C, capacity;

- $\mathrm{k}_{\mathrm{J}}$, jam density;

- L, link available width. Variables in the gap-acceptance model at non-signalized nodes are:

- $\mathrm{t}^{\prime}$, arrival time of vehicle at the node;

- $G_{C R, n}(t)$, critical gap for vehicle $\mathrm{n}$ at time $\mathrm{t}$, between $\mathrm{t}^{\prime}$ and $\mathrm{T}_{\mathrm{n}}$;

- m, type of vehicle manoeuvre (straight through, left turn, right turn);

- $\mathrm{nl}$, number of opposing lanes for the vehicle to cross. Parameters of the gap-acceptance model at non-signalized nodes are:

- $T_{n}$, maximum waiting time for vehicle $n$ starting from $t$, after which the vehicle starts the manoeuvre;

- $\mathrm{G}_{\mathrm{CR}, \mathrm{n}}$, critical gap for vehicle $\mathrm{n}$ at time $\mathrm{t}^{\prime}$;

- $\mathrm{G}_{\mathrm{n}}^{\mathrm{b}}$, value of critical gap if the vehicle executes a straight through manoeuvre and if the conflicting link, with higher prority, has a single lane;

- $\Delta G_{n}(m, n l)$, increment of critical gap for vehicle $\mathrm{n}$ due to a more complex manoeuvre than the straight through one (left turn, right turn) and when $\mathrm{nl}>1$.

Variable of path choice model is the probability of choosing the generic path $\mathrm{w}, \mathrm{p}_{\mathrm{n}}(\mathrm{w})$.

Parameters of the path choice model are:

- w, generic path;

- $\mathrm{I}_{\mathrm{in}}$, choice set for user (vehicle) $\mathrm{n}$.

\subsection{Model specification}

The car-following model $[5,6]$, is a relationship between spatial headway $\mathrm{h}$ and speed v:

where

$$
\mathrm{h}=\alpha_{1}+\left[\alpha_{2} /\left(\mathrm{v}_{0}-\mathrm{v}\right)\right]+\alpha_{3} \mathrm{v}
$$

$$
\alpha_{1}=\alpha_{4} \alpha_{2}
$$




$$
\begin{gathered}
\alpha_{2}=\left(1 / \mathrm{k}_{\mathrm{J}}\right)\left[1 /\left(\alpha_{4}+1 / \mathrm{v}_{0}\right)\right] \\
\alpha_{3}=\left[-\alpha_{1}+\mathrm{v}_{0} / \mathrm{C}-\left(\alpha_{2} /\left(\mathrm{v}_{0}-\mathrm{v}_{\mathrm{CR}}\right)\right)\right] / \mathrm{v}_{\mathrm{CR}} \\
\alpha_{4}=\left(2 \mathrm{v}_{\mathrm{CR}}-\mathrm{v}_{0}\right) /\left(\mathrm{v}_{0}-\mathrm{v}_{\mathrm{CR}}\right)^{2}
\end{gathered}
$$

with $\alpha_{1}, \alpha_{2}, \alpha_{3}$ and $\alpha_{4}$ parameters to be calculated for each link where $v_{0}, v_{C R}, C$ and $\mathrm{k}_{\mathrm{J}}$ are known. They can be expressed through the following equations:

$$
\begin{aligned}
\mathrm{k}_{\mathrm{J}} & =\beta_{1} \\
\mathrm{v}_{0} & =\beta_{2} \mathrm{~L} \\
\mathrm{v}_{\mathrm{CR}} & =\beta_{3} \mathrm{v}_{0} \\
\mathrm{C} & =\beta_{4} \mathrm{~L}
\end{aligned}
$$

From eqn (1) and given that spatial headway $h$ is the reciprocal of density $k$, density-speed relationship (10) was derived and inverted to obtain the densityspeed relationship (11):

$$
\begin{gathered}
\mathrm{k}=1 / \mathrm{h}=1 / \alpha_{1}+\left[\alpha_{2} /\left(\mathrm{v}_{0}-\mathrm{v}\right)\right]+\alpha_{3} \mathrm{v} \\
\mathrm{v}=\left(-\left(\left(\alpha_{3} \mathrm{v}_{0}-\alpha_{1}\right) \mathrm{k}+1\right)+\left(\left(\left(\alpha_{3} \mathrm{v}_{0}-\alpha_{1}\right) \mathrm{k}+1\right)^{2}+\right.\right. \\
\left.\left.-4\left(\alpha_{3} \mathrm{v}_{0}\right)\left(\left(\alpha_{1} \mathrm{v}_{0}+\alpha_{2}\right) \mathrm{k}-\mathrm{v}_{0}\right)\right)^{0.5}\right) / 2 \alpha_{3} \mathrm{v}_{0}
\end{gathered}
$$

The gap-acceptance model, based on the definition of critical gap for vehicle $\mathrm{n}$ at time $t$ between $t^{\prime}$ and $T_{n}$, is deterministic and has the following equation:

$$
G_{C R, n}(t)=\mathrm{G}_{\mathrm{CR}, \mathrm{n}}^{\prime}-G_{C R, n}^{\prime}\left(t-t^{\prime}\right) /\left(\mathrm{T}_{\mathrm{n}}-\mathrm{t}^{\prime}\right) \quad\left(\mathrm{t}^{\prime} \leq \mathrm{t} \leq \mathrm{T}_{\mathrm{n}}\right)
$$

where

$$
\mathrm{G}_{\mathrm{CR}, \mathrm{n}}^{\prime}=G_{C R, n}^{\prime}(m, n l)=\mathrm{G}_{\mathrm{n}}^{\mathrm{b}}+\Delta G_{n}(m, n l)
$$

Path choice model [8] estimates probabilty $\mathrm{p}_{\mathrm{n}}(\mathrm{w})$ through:

$$
\mathrm{p}_{\mathrm{n}}(\mathrm{w})=\mathrm{p}_{\mathrm{n}}\left(\mathrm{w}, \mathrm{I}_{\mathrm{in}}\right)=\Sigma_{\text {Iin }} \mathrm{p}_{\mathrm{n}}\left(\mathrm{w} / \mathrm{I}_{\text {in }}\right) \cdot \mathrm{p}_{\mathrm{n}}\left(\mathrm{I}_{\text {in }}\right)
$$

with

$\mathrm{p}_{\mathrm{n}}\left(\mathrm{I}_{\mathrm{in}}\right)$, probability of choice set $\mathrm{I}_{\mathrm{in}}$;

$\mathrm{p}_{\mathrm{n}}\left(\mathrm{w} / \mathrm{I}_{\mathrm{in}}\right)$, conditional probability of the generic path $\mathrm{w}$ given the choice set $\mathrm{I}_{\mathrm{in}}$.

\section{Experimentation}

One of the project activities was to organize and execute a real simulation of evacuation due to a forthcoming disaster in the experimental test site of Melito Porto Salvo (Reggio Calabria, Italy). Melito Porto Salvo is a town in the province of Reggio Calabria, in the south of Italy. It lies on the Ionian coast, 20 $\mathrm{km}$ from Reggio Calabria. The municipality has an area of $35.30 \mathrm{~km}^{2}, 10483$ inhabitants and 2432 employees.

The evacuation area is part of the central area of the town, where public offices (town hall, primary school, etc.), residential and commercial activities are located. It has an area of about $0.04 \mathrm{~km}^{2}, 57$ buildings, 255 residents, 65 households and 225 employees. Evacuation was performed during the morning 
rush-hour of a working day in accordance with the emergency plan drawn up by the Civil Protection Department. The real simulation allowed us to obtain data for model calibration.

\subsection{Data acquisition}

Evacuation of the population with motorized modes was filmed through a system of videocameras located on some selected links of the road network in order to monitor the evolution of traffic flow inside the evacuation area. The location of the main videocameras on road network is reported in figure 1.

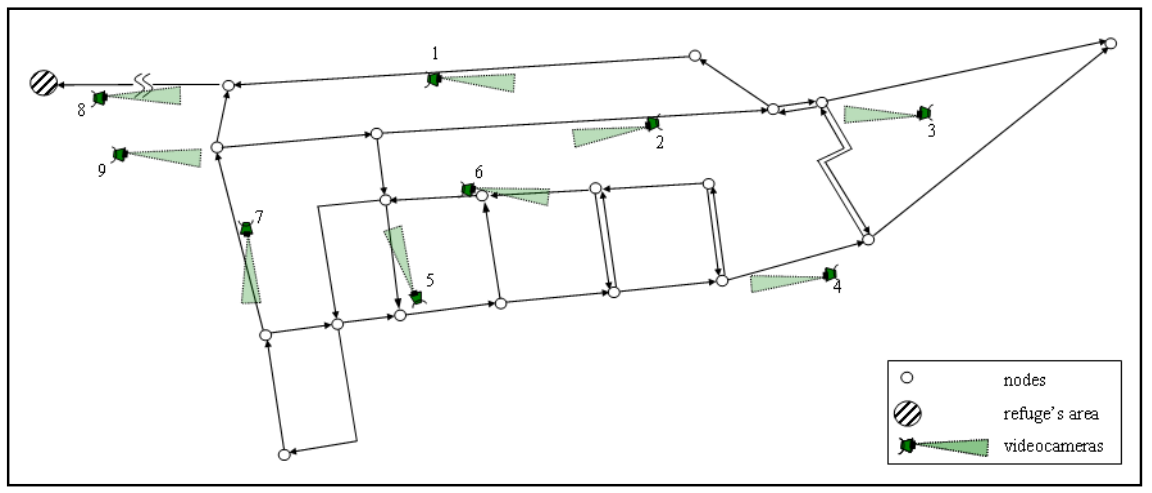

Figure 1: Videocamera location on the road network.

Traffic flow data were extracted in the laboratory from traffic scenes recorded by videocameras. The traffic flow variables observed were:

- vehicle running time, calculated as time spent by a vehicle crossing through two predefined road sections at known fixed distance along the link;

- $\quad$ vehicle counts on a predefined road section.

From the observed variables the following variables were estimated:

- $\quad$ vehicle speed $\left(\mathrm{v}_{\text {est }}\right)$, as the ratio of distance between the two road sections to vehicle running time;

- traffic flow $\left(\mathrm{f}_{\text {est }}\right.$ ), as the number of vehicles travelling on a predefined road section in a time unit;

- density $\left(\mathrm{k}_{\text {est }}\right)$, as the ratio between $\mathrm{f}_{\text {est }}$ and $\mathrm{v}_{\text {est }}$.

Speeds and densities were estimated from observations of the three roads monitored by videocameras 4,7 and 8 (see figure 1), with different available link width $(3.5 \mathrm{~m}, 4.0 \mathrm{~m}$ and $5.0 \mathrm{~m}$ respectively) and selected to obtain data related to uncongested and congested traffic flow conditions.

\subsection{Model calibration and validation}

Estimated speeds and densities were used to calibrate the proposed car-following model reported in eqn 11 whose parameters are reported in eqns (6)-(9). Parameter calibration was carried out with the Least Squares Method that has the 
property of minimizing total square differences between estimated values and values provided by the model whose parameters have to be known:

$$
\begin{gathered}
\text { objective function: Minimizing } \sum_{\mathrm{i}=1 \ldots \mathrm{N}}\left(\mathrm{v}_{\mathrm{i}, \text { est }}-\mathrm{v}_{\mathrm{i}}\right)^{2} \\
\text { variables: } \beta_{1}, \beta_{2}, \beta_{3}, \beta_{4}
\end{gathered}
$$

where

- $\quad \mathrm{N}$ is the number of observations;

- $v_{i, \text { est }}$ is the value of estimated speed for the generic vehicle $i$;

- $\mathrm{v}_{\mathrm{i}}$ is the value of speed provided by the the model (eqn 11) for the generic vehicle $\mathrm{i}$.

Over 450 observations were used for calibration. Subsequently the calibrated model was validated through the following statistical indicators:

- informal tests on calibrated parameter signs;

- MSE:

$$
\operatorname{MSE}=\left(\sum_{\mathrm{i}=\mathrm{N}}\left(\mathrm{v}_{\mathrm{i}, \text { est }}-\mathrm{v}_{\mathrm{i}}\right)^{2}\right) / \mathrm{N}
$$

- $\quad$ RMSE \%:

$$
\operatorname{RMSE} \%=100 \cdot\left(\left(\sum_{\mathrm{i}=\mathrm{N}}\left(\mathrm{v}_{\mathrm{i}, \text { est }}-\mathrm{v}_{\mathrm{i}}\right)^{2}\right) / \mathrm{N}\right)^{1 / 2} /\left(\sum_{\mathrm{i}=\mathrm{N}} \mathrm{v}_{\mathrm{i}, \text { est }} / \mathrm{N}\right)
$$

Figure 2 shows the calibrated model, which was applied on the obseved links of known available width, and the values of the statistical indicators.

\section{Application}

A computer application was performed to reproduce evacuation observed in the test site of Melito Porto Salvo. Road transport supply was simulated considering the following steps: delimitation of evacuation area; definition of zoning and origin centroids; graph construction and application of car-following model (11) with calibrated parameters.

Demand was simulated through the origin-destination matrix estimated in [13]. Moreover, the transport demand crossing the evacuation area was estimated in order to reproduce link flows on network in ordinary conditions during the morning rush-hour of a working day. Demand-supply interaction was performed through the software Integration [11] which uses a microscopic DTA procedure. Some transportation network performance indicators are defined and estimated.

\subsection{Microsimulation procedure}

The area to evacuate was subdivided into eleven traffic zones. One of these represents the primary school that was not considered for the simulation because no private vehicle demand was generated from it.

The road network simulates the road system of the evacuation area. The graph (figure 3) has 37 nodes, 11 of which are origins, and 66 links. The intersections are all non-signalized. 
Application on link monitored by videocamera 4

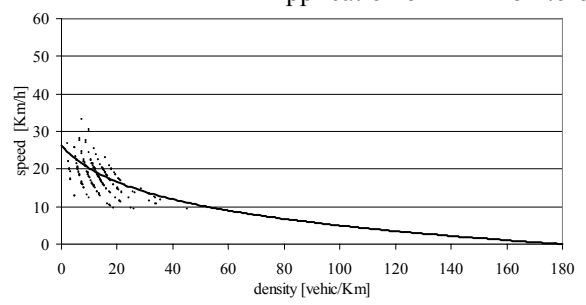

\begin{tabular}{ll}
\hline L & $3.5 \mathrm{~m}$ \\
MSE & 13.30 \\
RMSE \% & 20.39 \\
\hline
\end{tabular}

Application on link monitored by videocamera 7

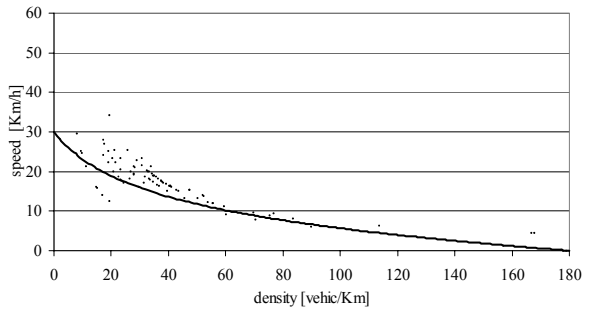

\begin{tabular}{lc}
\hline $\mathrm{L}$ & $4.0 \mathrm{~m}$ \\
MSE & 16.53 \\
RMSE \% & 23.68 \\
\hline
\end{tabular}

Application on link monitored by videocamera 8

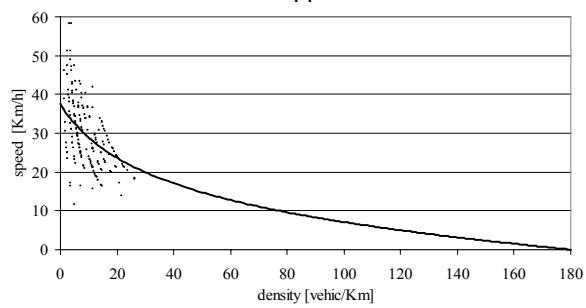

\begin{tabular}{ll}
\hline $\mathrm{L}$ & $5.0 \mathrm{~m}$ \\
MSE & 52.66 \\
RMSE \% & 24.61 \\
\hline
\end{tabular}

Figure 2: Application of car-following model on links monitored by videocameras 4,7 and 8 (see figure 1 ).

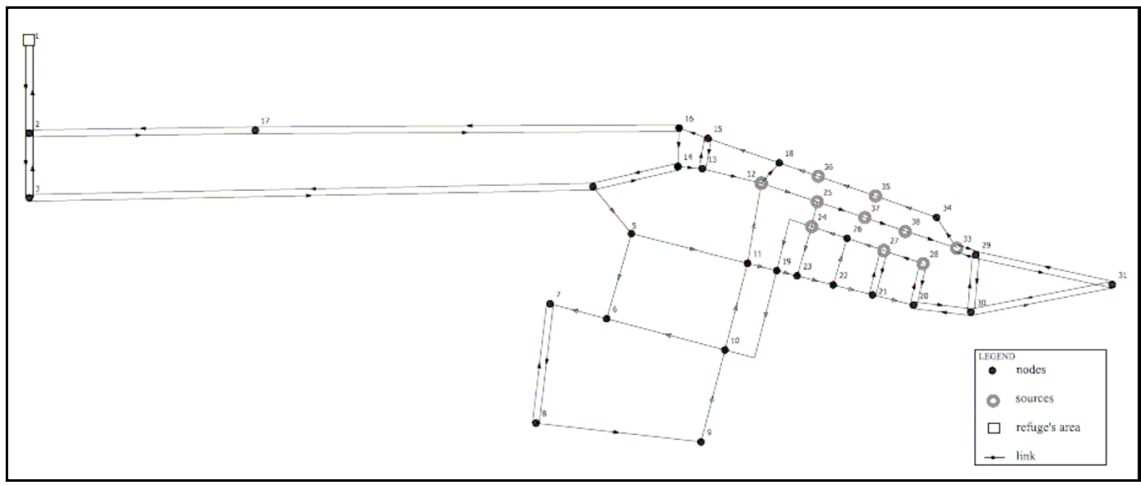

Figure 3: Graph. 
Private vehicle demand was estimated in 205 vehicles for the simulation period.

For the assignment the following specifications were made:

- $\quad$ private vehicle demand for each origin-destination pair was generated with a uniform distribution;

- $\quad$ some links inside evacuation area were closed in order to simulate the real supply changes made by the members of the emergency assistance during the test.

\subsection{Indicators}

Performance indicators can be divided into:

- demand-supply interaction indicators, for global analysis of the road transport system: total vehicle travel distance on the network $\left(\mathrm{L}_{\text {tot }}\right)$, average travel distance per vehicle $\left(\mathrm{L}_{\mathrm{a}}\right)$, total vehicle travel time on the network $\left(\mathrm{T}_{\text {tot }}\right)$, average travel time per vehicle $\left(\mathrm{T}_{\mathrm{a}}\right)$, vehicle evacuation time or time at which the last vehicle evacuates from the network $\left(\mathrm{T}_{\text {lve }}\right)$, vehicle average speed on the network $\left(\mathrm{V}_{\mathrm{a}}\right)$;

- evolution indicators, for the analysis of transport system evolution during evacuation: time profile of number of vehicles on the network $\left(\mathrm{N}_{\text {net }}\right)$, time profile of number of vehicles that reach each destination $\left(\mathrm{N}_{\text {safe }}\right)$.

Table 1 reports the values of the demand-supply interaction indicators. Of these, the most significant are vehicle evacuation time $\left(\mathrm{T}_{\text {lve }}\right)$ of 24.10 minutes and average travel time per vehicle $\left(\mathrm{T}_{\mathrm{a}}\right)$ of 3.78 minutes.

In figure 4 the time profile of the number of vehicles on the network is represented. It initially increases and peaks after five minutes, thereafter it shows a decreasing trend.

Table 1: $\quad$ Demand-supply interaction indicators.

\begin{tabular}{lccr}
\hline \multicolumn{1}{c}{ Indicator } & Symbol & Unit & \\
\hline Total vehicle travel distance on the network & $\mathrm{L}_{\text {tot }}$ & vehic $\cdot \mathrm{km}$ & 402.44 \\
Average travel distance per vehicle & $\mathrm{L}_{\mathrm{a}}$ & $\mathrm{km}$ & 1.96 \\
Total vehicle travel time on the network & $\mathrm{T}_{\text {tot }}$ & vehic $\cdot \mathrm{min}$ & 775.10 \\
Average travel time per vehicle & $\mathrm{T}_{\mathrm{a}}$ & $\mathrm{min}$ & 3.78 \\
Vehicle evacuation time & $\mathrm{T}_{\mathrm{lve}}$ & $\mathrm{min}$ & 24.10 \\
Vehicle average speed on the network & $\mathrm{V}_{\mathrm{a}}$ & $\mathrm{km} / \mathrm{h}$ & 31.17 \\
\hline
\end{tabular}

\section{Conclusions and prospects}

One of the activities of the SICURO project concerns the specification and calibration of a system of models able to simulate transport supply and demandsupply interaction when a population has to be evacuated due to a forthcoming disaster. In this context Dynamic Traffic Assignment (DTA) methods and procedures become necessary. 


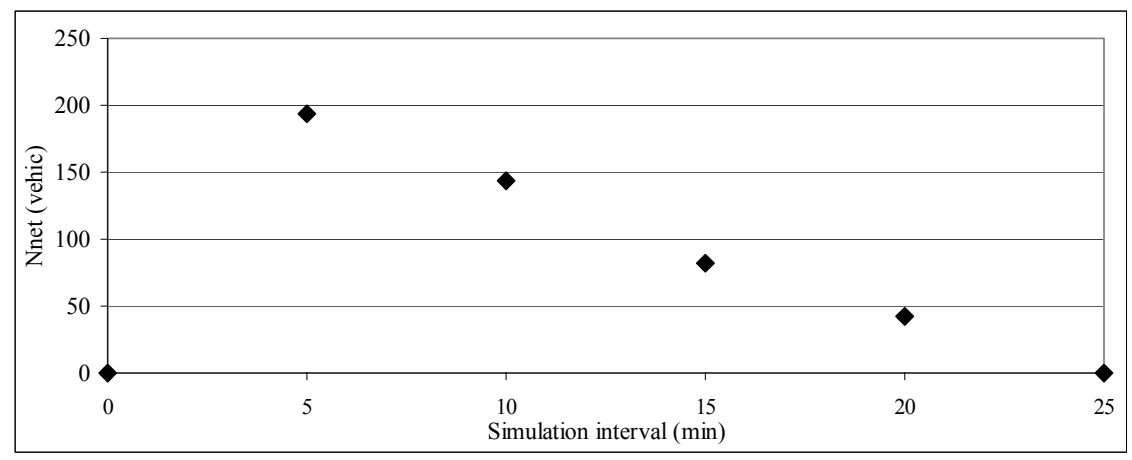

Figure 4: $\quad$ Time profile of number of vehicles on the network $\left(\mathrm{N}_{\text {net }}\right)$.

In the paper we presented microsimulation models and procedures for analysing a road transportation system in emergency conditions.

Parameters of the car-following model were calibrated with vehicle speeds and densities, experimentally estimated from observed traffic flow data related to uncongested and congested traffic flow conditions. These data were extracted from a real simulation of evacuation conducted in the test site of Melito Porto Salvo (Reggio Calabria, Italy). A computer application was performed in order to reproduce the observed evacuation phases.

Possible future developments concern model calibration for other types of roads (in extra-urban areas) and the performance of simulation over wider urban areas.

\section{References}

[1] Velonà, P. \& Vitetta, A., Evolution of an urban transportation system in emergency conditions: analysis through a pseudo-dynamic assignment model. Environmental Health Risk II, C. A. Brebbia, D. Fayziera (eds), WIT Press, Boston, pp. 217-226, 2003.

[2] Di Gangi, M. \& Velonà, P., Use of a mesoscopic dynamic assignment model for approaching the evolution of an urban transportation system in emergency conditions. Environmental Health Risk II, C. A. Brebbia, D. Fayziera (eds), WIT Press, Boston, pp. 227-236, 2003.

[3] Chandler, R., Herman \& R., Montroll, E., Traffic dynamics: studies in car-following. Operations Research 6, pp. 165-178, 1958.

[4] Zhang, Y., Owen L.E. \& Clark J.E., A multiregime approach for microscopic traffic simulation. $78^{\text {th }}$ Annual Meeting Transportation Research Board. Washington D.C. USA, 1999.

[5] Ahmed, K. I., Ben-Akiva M. E., Koutsopoulos H. N. \& Mishalani R. G., Models of Freeway Lane Changing and Gap Acceptance Behaviour. Proceeding of ISTTT. Lyon, 1996. 
[6] Cantarella, G.E. \& Festa, D.C. (eds), Modelli e Metodi per l'Ingegneria del Traffico. Collana Trasporti. Ed. FrancoAngeli, 1998.

[7] Daganzo, C.F., Estimation of gap acceptance parameters within and across the population from direct roadside observation. Transportation Research Part B 15B, pp. 1-15, 1981.

[8] Cascetta, E., Transportation systems engineering: theory and methods, Kluwer, 2001.

[9] Musolino, G. \& Vitetta, A., Microscopic approach for the evaluation of an urban transport system in emergency conditions. Environmental Health Risk II, C.A. Brebbia, D. Fayzieva (eds). WIT Press, Boston, pp. 237-246, 2003.

[10] Musolino, G. \& Vitetta, A., Analisi e gestione di una rete di trasporto in condizioni di emergenza mediante procedure di microsimulazione. Metodi quantitativi per l'analisi di un sistema di trasporto in condizioni di emergenza, Francesco Russo (ed.). Strumenti per l'analisi dei sistemi di trasporto. Ed. FrancoAngeli, Milan, 2004.

[11] Van Aerde, M., A Single regime Speed-Flow-Density Relationship for Congested and uncongested Highways. $78^{\text {th }}$ Annual Meeting Transportation Research Board. Washington D.C. USA, 1997.

[12] Van Aerde, M. \& Transportation Research Group, INTEGRATIONRelease 2.30. User's Guide. Volume I, II, III. M. Van Aerde \& Assoc., Ltd, 2000.

[13] Russo, F., \& Chilà, G., Safety of users in road evacuation: demand model. In the same proceedings, 2007. 